\title{
DEVELOPMENT AND VALIDATION OF SPECTROPHOTOMETRIC METHODS FOR THE DETERMINATION AND SPECTROSCOPIC CHARACTERIZATION OF VILDAGLIPTIN USING I-ACCEPTORS IN PHARMACEUTICAL PREPARATIONS
}

\author{
SERIFE EVRIM KEPEKCI TEKKEL $\dot{I}^{1}$, FATEMEH BAHADORI \\ ${ }^{1}$ Bezmialem Vakif University Faculty of Pharmacy Department of Analytical Chemistry, 34093, Fatih, İstanbul, Turkey \\ ${ }^{2}$ Bezmialem Vakif University Faculty of Pharmacy Department of Pharmaceutical Biotechnology, 34093, Fatih, Istanbul, Turkey
}

\begin{abstract}
Three simple, quick and sensitive methods are described for the spectrophotometric determination of vildagliptin (VLD) in pharmaceutical preparations. The methods are based on formation of colored charge transfer (CT) complexes between VLD as n-electron donor and chloranilic acid (CA), tetrachloro-1,4benzoquinone (p-chloranil), 7,7,8,8-tetracyanoquinodimethane (TCNQ) as $\pi$-acceptors. The colored products were quantitated spectrophotometrically at 520,535 and $842 \mathrm{~nm}$ for CA, p-chloranil and TCNQ methods, respectively. Optimization of different experimental conditions were investigated. Beer's law was obeyed in the concentration range of $20-250 \mu \mathrm{g} \mathrm{mL}^{-1}, 25-400 \mu \mathrm{g} \mathrm{mL}^{-1}$ and $20-500 \mu \mathrm{g} \mathrm{mL}-1$ for CA, p-chloranil and TCNQ methods, respectively. The formation of the CT-complexes and the sites of interactions were confirmed by elemental analysis using IR, ${ }^{1} \mathrm{H}$ NMR spectroscopy. Validity of the methods in terms of specificity, linearity, accuracy, precision, robustness, limit of detection and limit of quantitation were evaluated. Good recoveries were obtained for all of the methods indicating that no interference was observed from concomitants usually present in dosage forms. The methods were applied successfully to the determination of VLD in pharmaceutical preparations.
\end{abstract}

Keywords Charge Transfer Complex, IR spectroscopy, NMR spectroscopy, Pharmaceutical Preparation Spectrophotometry, $\pi$-acceptors, Validation, Vildagliptin

\section{INTRODUCTION}

Diabetes is a chronic disease that affects the multitude of physiologic pathways known to work together to achieve glycemic homeostasis. It is estimated that approximately $6.6 \%$ of the world's population had diabetes in 2010 , and this figure is projected to increase to $7-8 \%$ by 2030 [1]. Several DPP-4 inhibitors ("gliptins") have been approved by the US Food and Drug Administration (FDA) for the treatment of type 2 diabetes mellitus. These agents have reported efficacy in reducing hemoglobin Alc levels as monotherapy or in combination with other commonly prescribed glucose lowering medications [2]. Vildagliptin (VLD), a member of this class, has been shown good overall safety and tolerability and improving glycaemic control when given as monotherapy or combination therapy [3-4]. VLD improves $\beta$ and $\alpha$-cell sensitivity to glucose by increasing concentrations of active GLP1 [5]. This results in glucose-sensitive modulation of insulin and glucagon secretion, improving both fasting and postprandial glycaemia, with a low risk of hypoglycaemia. A very low incidence of hypoglycaemia has consistently been reported with VLD across the disease spectrum $[6,7]$.

Only three HPLC methods were reported for the determination of VLD [8-10]. There is not any spectrophotometric method in literature. Therefore, developing simple, sensitive and precise spectrophotometric methods was aimed. Charge-transfer (CT) reactions have been frequently used spectrophotometrically in the determination of drugs that reacts with some electron acceptors ( $\pi$-acceptors) such as chloranilic acid (CA), tetrachloro-1,4benzoquinone (p-chloranil) and 7,7,8,8-tetracyanoquinodimethane (TCNQ) [11-19].

This paper describes the formation of CT complexes between VLD as an electron donor and CA, p-chloranil and TCNQ. The nature and structure of the final products in solid phase have been characterized using ${ }^{1} \mathrm{H}$ NMR, FTIR spectroscopy.

\section{EXPERIMENTAL}

Spectrophotometric measurements were carried out by using a Hitachi spectrometer Model U-2900 equipped with xenon lamp and $1 \mathrm{~cm}$ quartz cells.

The FTIR spectra of the reactants and the resulting CT complexes were recorded using $\mathrm{KBr}$ disc on Thermo Nicolet 6700 FTIR spectrometer. ${ }^{1} \mathrm{H}$ NMR spectra of the CT complexes, donors and acceptors were recorded in DMSO using Varian Mercury ( $\left.{ }^{1} \mathrm{H}: 400 \mathrm{mHz}\right) 400 \mathrm{NMR}$ Spectrometer.

\section{Reagents and solutions}

VLD was kindly supplied by Megafine (India) and its pharmaceutical preparation (Galvus ${ }^{\circledR}$ ) containing $50 \mathrm{mg}$ of VLD per tablet was obtained from local drug store. All chemicals and reagents were of analytical-reagent grade.

Stock solution of VLD $\left(1 \mathrm{mg} \mathrm{mL}^{-1}\right)$ was prepared in acetonitrile.

TCNQ (Fluka-Neu-Ulm, Germany), CA and p-chloranil Merck (Darmstadt, Germany) were freshly prepared as $0.2 \%, 0.1 \%(\mathrm{w} / \mathrm{v})$ solutions in acetonitrile and $1 \%(\mathrm{w} / \mathrm{v})$ solution in acetone respectively; the solutions were stable for 1 week at $4^{\circ} \mathrm{C}$.

\section{General Procedure}

Into $5 \mathrm{~mL}$ calibrated flasks $0.10-1.25 \mathrm{~mL}, 0.125-2.0 \mathrm{~mL}$ and $0.10-2.5 \mathrm{~mL}$ aliquots of VLD stock solution was added for CA, p-chloranil, and TCNQ methods, respectively. The volume was brought to $1.25 \mathrm{~mL}$ (for CA), $2.0 \mathrm{~mL}$ (for p-chloranil) and $2.5 \mathrm{~mL}$ (for TCNQ) with acetonitrile and $0.5 \mathrm{~mL}$ of CA, $0.5 \mathrm{~mL}$ of p-chloranil, $1 \mathrm{~mL}$ TCNQ reagents were added. The reaction mixture was heated for $5 \mathrm{~min}$ at $80^{\circ} \mathrm{C}$ for TCNQ method, and allowed to stand for 5 $\mathrm{min}$ at room temperature for both $\mathrm{CA}$ and $\mathrm{p}$-chloranil methods. After cooling and diluting to volume $5 \mathrm{~mL}$ with acetonitrile, the absorbances were measured at 520,535 and $842 \mathrm{~nm}$ for CA, p-chloranil and TCNQ respectively, against a reagent blank prepared in the same manner. The calibration graph of each method was prepared by plotting absorbance versus concentration of VLD.

Synthesis of the solid CT complexes

The solid CT complexes were synthesed by adding a saturated solution of VLD $\left(303.4 \mathrm{mg}, 1 \times 10^{-3} \mathrm{~mol}\right.$ ) in acetonitrile to each reagent solution (to a saturated solution of CA (313.5. mg, $\left.1.5 \times 10^{-3} \mathrm{~mol}\right)$, p-chloranil $\left(328 \mathrm{mg}, 1.3 \times 10^{-}\right.$ $\left.{ }^{3} \mathrm{~mol}\right)$, TCNQ $\left(204 \mathrm{mg}, 1 \times 10^{-3} \mathrm{~mol}\right)$. The mixtures were stirred for about $30 \mathrm{~min}$ and then filtered off to avoid the contamination with any unreacted species. The solutions were then left nearly $2 \mathrm{~h}$ to obtain the solid CT complexes, filtered and washed several times with minimum amounts of acetonitrile in order to remove the residual reagents and drug substance.

\section{Assay procedure for tablets}

Ten tablets were transferred to a $250 \mathrm{~mL}$ volumetric flask. About $125 \mathrm{~mL}$ of acetonitrile were added and then extraction was performed mechanically for 20 minutes and sonicated for 20 more minutes. The volume was brought to 250 $\mathrm{mL}$ with acetonitrile and the final solution was filtered. Aliquots of the filtrate was diluted further with acetonitrile and then preceded as described under preparation of the calibration curve. The nominal contents of the tablets were calculated using either the calibration graph or the corresponding regression equation. 


\section{RESULTS AND DISCUSSION}

As a product of the interaction between VLD and CA, p-chloranil, TCNQ; CT complexes were occurred which absorb light at 520, 535 and $842 \mathrm{~nm}$, respectively (Fig. 1).

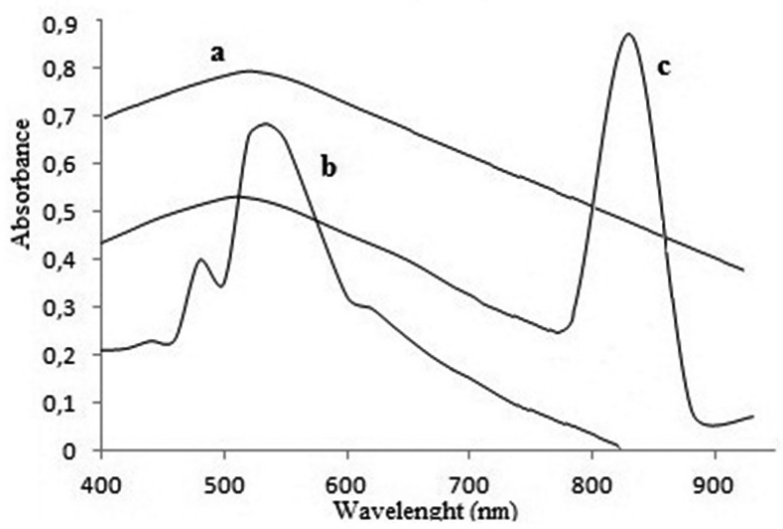

Fig.1 (a) Absorption spectrum of $150 \mu \mathrm{g} \mathrm{mL^{-1 }}$ VLD-CA complex against

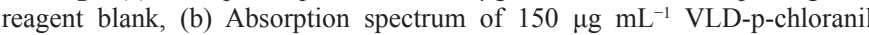
complex reagent against reagent blank and (c) Absorption spectrum of $250 \mu \mathrm{g}$ $\mathrm{mL}^{-1}$ VLD-TCNQ complex reagent against reagent blank.

The CT reactions are shown in Figure 2

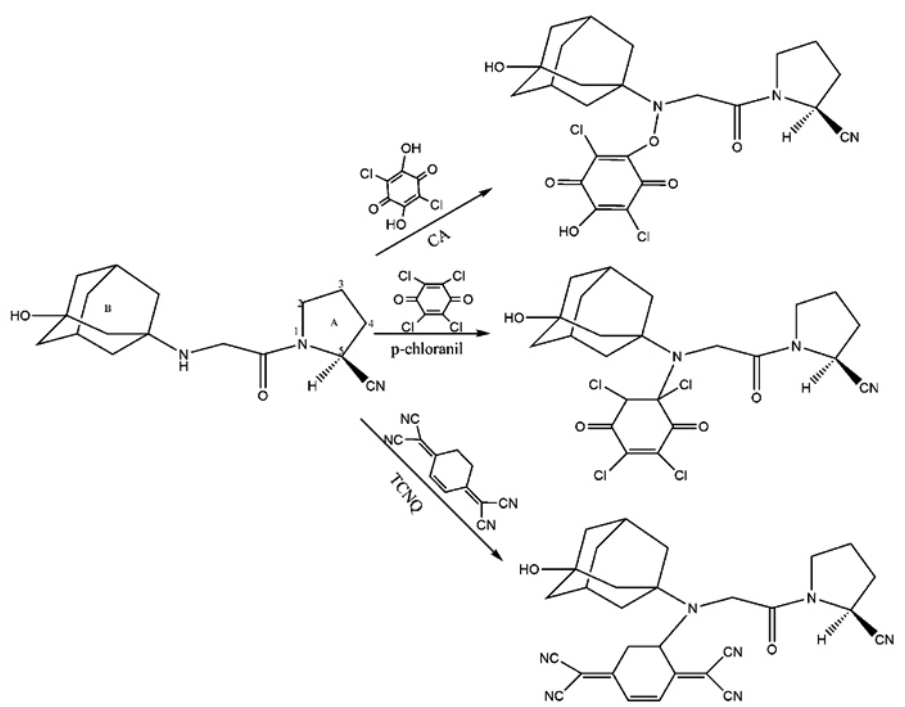

Fig.2 The reactions between VLD and $\pi$-acceptors in acetonitrile.

The effect of different parameters on the complex formation was studied to determine optimum conditions for all of the assay procedures.

\section{Optimization procedure}

Choice of solvent

Different solvents included acetonitrile, chloroform, methanol, acetone, ethanol, 1,4-dioxane, and methylene chloride were investigated in order to select the suitable solvent for CT formation medium. Acetonitrile (for chloranilic acid and TCNQ) and acetonitrile: acetone mixture (1:1) (for p-chloranil) were considered to be ideal solvents for the most effective complex formation reaction.

Reagent concentration

The effect of reagent ( $\pi$-acceptor) concentration (by volume) on the reactions were investigated. Different volumes of TCNQ $(0.2 \%(\mathrm{w} / \mathrm{v}), \mathrm{CA}$ $(0.1 \%(\mathrm{w} / \mathrm{v})$ and $\mathrm{p}$-chloranil $(1 \%(\mathrm{w} / \mathrm{v})$ were added to a fixed concentration of VLD. $0.5 \mathrm{~mL}$ of CA and p-chloranil and $1 \mathrm{~mL} \mathrm{TCNQ}$ solution was found to be sufficient for quantitative determination of VLD (Fig. 3).

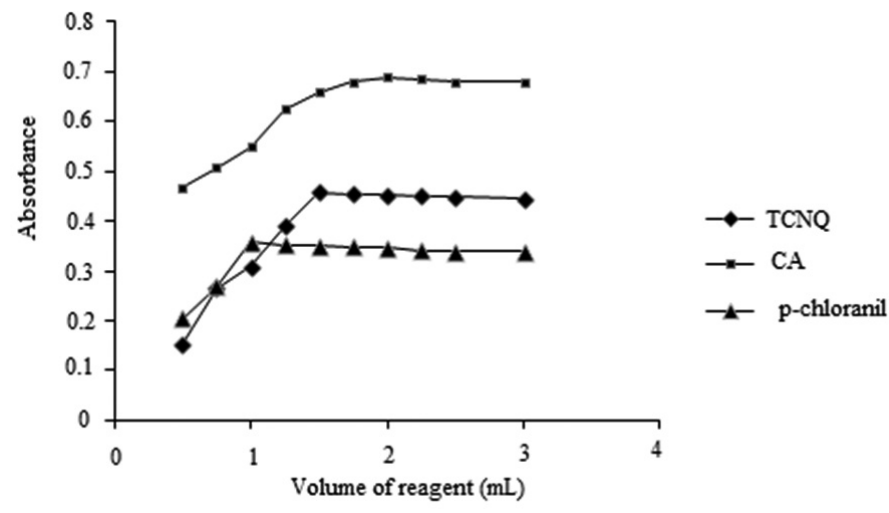

Fig.3 Effect of volumes of CA $(0.2 \%$, w/v) and p-chloranil $(0.2 \%$, w $/ v)$ and TCNQ $(0.2 \%, \mathrm{w} / \mathrm{v})$ on the development of the reaction product of VLD with $(\mathbf{\Delta})$ CA, (घ) p-chloranil and (») TCNQ.

\section{Reaction time}

The optimum reaction time for all of the methods was determined by investigating the color development at room temperature and $60-80^{\circ} \mathrm{C}$. Complete color development was attained after $5 \mathrm{~min}$ for TCNQ at $80^{\circ} \mathrm{C}$, whereas for p-chloranil and CA, room temperature for $5 \mathrm{~min}$. was optimum (Fig 4). The colors remained stable for $12 \mathrm{~h}$ for all complexes.

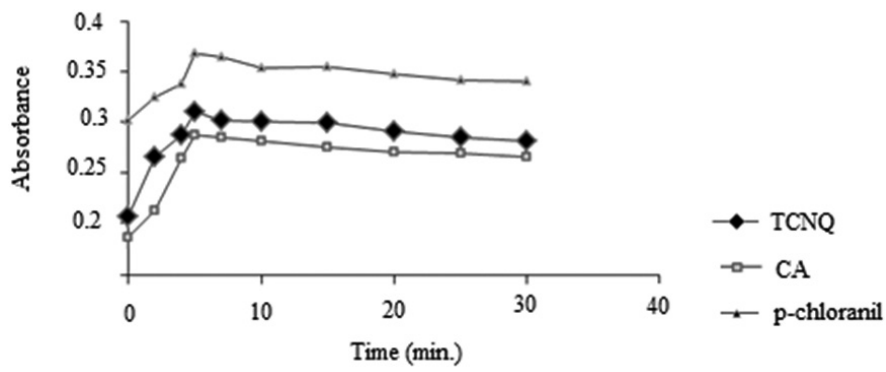

Fig.4 The effect of temperature and time of heating on the reaction of $\operatorname{TCNQ}\left(\bullet\right.$ at $\left.80^{\circ} \mathrm{C}\right), \mathrm{CA}(\boldsymbol{\Lambda}$, at room temperature) and p-chloranil $(\boldsymbol{\bullet}$, at room temperature) reagents with VLD.

Stoichiometry of the reaction

The molar ratio of the reagent in reaction mixture was studied for all methods according to Job's method of continuous variation [20]. Utilizing equimolar solutions of VLD and the reagents provided the most effective reactions (the reaction stoichiometry was found to be a good approximation 1:1 ratio (drug/ reagent) for all methods).

\section{Method validation}

The developed analytical methods were validated in accordance with the ICH guideline Q2 (R1) [21]. Under the described experimental conditions, calibration graphs were constructed for all of the methods and Table 1 summarizes the values for Beer's law limits, regression equation, correlation coefficients, molar absorptivity, Sandel's sensitivity, limit of detection (LOD) and limit of quantification (LOQ) for each method. As can be seen from the Table 1, linear relationship for all methods was found between the absorbance at $\lambda_{\text {max }}$ and the concentration of the drug in the ranges of $20-250 \mu \mathrm{g} \mathrm{mL}^{-1}, 25-$ $400 \mu \mathrm{g} \mathrm{mL}^{-1}$ and $20-500 \mu \mathrm{g} \mathrm{mL}^{-1}$ for CA, p-chloranil and TCNQ methods, respectively. The $\mathrm{CA}$ method was the most sensitive one, with a high $\varepsilon$ value. $\mathrm{LOD}$ and LOQ were determined using the formula: $\mathrm{LOD}$ or $\mathrm{LOQ}=\kappa \mathrm{SDa} / \mathrm{b}$, where $\kappa=3$ for LOD and 10 for LOQ, SDa is the standard deviation of the intercept, and $\mathrm{b}$ is the slope. The inter- and intra-day precisions were examined by analysis of VLD with concentrations of 20,100 and $250 \mu \mathrm{g} \mathrm{mL}^{-1}$ for CA method, 25, 100 and $400 \mu \mathrm{g} \mathrm{mL} \mathrm{m}^{-1}$ for $\mathrm{p}$-chloranil method and 20, 100 and $500 \mu \mathrm{g} \mathrm{mL}^{-1}$ for TCNQ method (each $n=5$ ) for seven consecutive days. The $\%$ RSD values for intra-day precision $\%$, and inter-day precision were found for all developed methods, which indicate good repeatability. The obtained results are summarized in Table 1. 
Table 1 Results of validation parameters for proposed methods.

\begin{tabular}{|c|c|c|c|}
\hline & Using CA reagent & $\begin{array}{l}\text { Using p-chloranil } \\
\text { reagent }\end{array}$ & $\begin{array}{l}\text { Using TCNQ } \\
\text { reagent }\end{array}$ \\
\hline Linearity range ${ }^{\mathrm{a}}\left(\mu \mathrm{g} \mathrm{mL}^{-1}\right)$ & $20-250$ & $25-400$ & $20-500$ \\
\hline Molar absorptivity $\left(1 \mathrm{~mol}^{-1} \mathrm{~cm}^{-1}\right)$ & $3.55 \times 10^{3}$ & $2.03 \times 10^{3}$ & $1.8 \times 10^{3}$ \\
\hline $\begin{array}{l}\text { Sandel's sensitivity }\left(\mu \mathrm{gcm}^{-2} \text { per }\right. \\
0.001 \text { absorbance unit) }\end{array}$ & 0.85 & 0.13 & 0.17 \\
\hline \multicolumn{4}{|l|}{ Precision } \\
\hline Intra-day ${ }^{\mathrm{b}}, \mathrm{RSD} \%$ & 0,95 & 0,87 & 0.68 \\
\hline Inter-day ${ }^{\mathrm{c}}, \mathrm{RSD} \%$ & 1.12 & 1.28 & 1.39 \\
\hline \multicolumn{4}{|l|}{ Regression equation ${ }^{\mathrm{d}}$} \\
\hline Slope \pm SD & $0.0034 \pm 0.00005$ & $0.0021 \pm 0.00001$ & $\begin{array}{l}0.0016 \pm \\
0.00003\end{array}$ \\
\hline Intercept \pm SD & $0.0187 \pm 0.00013$ & $0.0755 \pm 0.00019$ & $\begin{array}{l}0.0981 \pm \\
0.00023\end{array}$ \\
\hline Correlation coefficient, $r$ & 0.9995 & 0.9997 & 0.9994 \\
\hline $\operatorname{LOD}\left(\mu \mathrm{g} \mathrm{mL}^{-1}\right)$ & 0.12 & 0.28 & 0.43 \\
\hline $\operatorname{LOQ}\left(\mu \mathrm{g} \mathrm{mL}^{-1}\right)$ & 0.38 & 0.92 & 1.44 \\
\hline
\end{tabular}

To check accuracy of the proposed methods, standard addition technique was applied. A different amount of pure sample solution was added to three different concentrations of standard drug solutions and assayed. The percent recovery of the added standard to the assay samples was calculated from:

Recovery $\%=\left[\left(\mathrm{C}_{\mathrm{t}}-\mathrm{C}_{\mathrm{u}}\right) / \mathrm{C}_{\mathrm{a}}\right] \times 100$

where $\mathrm{C}_{1}$ is the total concentration of the analyte found, $\mathrm{C}$ is the concentration of the analyte present in the formulation, and $\mathrm{C}$ is the concentration of the pure analyte added to the formulation. The results of analysis of the commercial dosage forms and the recovery study were shown in Table 2 . The average percent recoveries obtained were quantitative $(101.11 \%, 101.46 \%$ and $101.33 \%$ for CA, p-chloranil and TCNQ methods, respectively), indicating good accuracy of the methods.

Table 2 Results of recovery studies by standard addition method.

\begin{tabular}{|c|c|c|c|c|c|}
\hline Method & $\begin{array}{l}\text { Amount taken } \\
\left(\mu \mathrm{g} \mathrm{mL}^{-1}\right)^{\mathrm{a}}\end{array}$ & $\begin{array}{c}\text { Amount } \\
\text { added } \\
\left(\mu \mathrm{g} \mathrm{mL}^{-1}\right)\end{array}$ & $\begin{array}{l}\text { Total amount } \\
\text { found }^{\mathrm{b}} \\
\left(\mu \mathrm{g} \mathrm{mL}^{-1}\right) \\
\left(\text { Mean } \pm \text { S.D. }^{\mathrm{c}}\right)\end{array}$ & Recovery (\%) & RSD (\%) \\
\hline \multirow{3}{*}{ Using CA reagent } & \multirow{3}{*}{100} & 20 & $120.32 \pm 1.14$ & 101.62 & 0.95 \\
\hline & & 100 & $200.147 \pm 1.58$ & 100.15 & 0.79 \\
\hline & & 150 & $252.360 \pm 2.58$ & 101.57 & 1.02 \\
\hline \multirow{3}{*}{$\begin{array}{l}\text { Using p-chloranil re- } \\
\text { agent }\end{array}$} & \multirow{3}{*}{100} & 25 & $125.47 \pm 1.34$ & 101.88 & 1.07 \\
\hline & & 100 & $201.66 \pm 1.87$ & 101.66 & 0.93 \\
\hline & & 300 & $402.54 \pm 2.56$ & 100.85 & 10.64 \\
\hline \multirow{3}{*}{ Using TCNQ reagent } & & 20 & $120.36 \pm 1.14$ & 101.80 & 0.95 \\
\hline & 100 & 200 & $302.54 \pm 1.58$ & 101.27 & 0.79 \\
\hline & & 400 & $503.65 \pm 3.87$ & 100.91 & 0.77 \\
\hline
\end{tabular}

The applicability of the proposed methods was tested by the determination of VLD in tablets. The obtained results are satisfactorily accurate and precise as indicated by the excellent \% recovery and $\mathrm{SD}<2$ (Table 3). Experiments showed that there was no interference from the additives and excipients, e.g. lactose, glucose, fructose, magnesium stearate and starch. 
Table 3 Analysis of VLD in tablet containing $50 \mathrm{mg}$ of the drug $(\mathrm{n}=5) 3.3$ IR spectra of the CT acceptor complexes.

\begin{tabular}{|c|c|c|c|}
\hline & $\begin{array}{c}\text { Using CA } \\
\text { reagent } \\
\left(\text { Mean } \pm \text { S.D. }^{c} \text { ) }\right.\end{array}$ & $\begin{array}{c}\text { Using p-chloranil } \\
\text { reagent } \\
\left(\text { Mean } \pm \text { S.D. }^{c} \text { ) }\right.\end{array}$ & $\begin{array}{c}\text { Using TCNQ } \\
\text { reagent } \\
\left(\text { Mean } \pm \text { S.D. }^{c} \text { ) }\right.\end{array}$ \\
\hline Mean \pm S.D & $50.45 \pm 0.31$ & $50.31 \pm 0.12$ & $50.34 \pm 0.09$ \\
\hline Recovery (\%) & 100.90 & 100.62 & 100.68 \\
\hline RSD (\%) & 0.61 & 0.23 & 0.17 \\
\hline
\end{tabular}

aGalvus tablet $(50 \mathrm{mg})$

${ }^{\mathrm{b}}$ Five independent analyses.

'Standard deviation

IR spectra of the CT Complexes VLD showed the expected -NH and -OH stretch at $3420 \mathrm{~cm}^{-1}$ as a broad peak of $-\mathrm{OH}$ stretching overlapped with the sharp stretching band of $-\mathrm{NH}$ group. Together with this the weak stretching band of $-\mathrm{C} \equiv \mathrm{N}$ at $2239 \mathrm{~cm}^{-1}$ and the amide like ketone stretching at 1650 $\mathrm{cm}^{-1}$ were observed. The C-O stretch at 1359 confirms the presence of the overlapped $-\mathrm{OH}$ group. The IR spectra of CA gives an $-\mathrm{OH}$ peak at $3233 \mathrm{~cm}^{-1}$, $\mathrm{C}=\mathrm{O}$ stretch at 1665 and $1626 \mathrm{~cm}^{-1}$ and $\mathrm{C}-\mathrm{O} 1359 \mathrm{~cm}^{-1}$ which coincides with previously reported data [21]. In the IR spectra of VLD-CA, the complete disappearance of $-\mathrm{NH}$ peak at $3420 \mathrm{~cm}^{-1}$ is observed while the broadened peak of $-\mathrm{OH}$ is still presented. On the other hand the $-\mathrm{OH}$ peak of $\mathrm{CA}$ at 3233 $\mathrm{cm}^{-1}$ is being recorded together with that of VLD. Previously the presence of $-\mathrm{NH}_{3}{ }^{+}$has been reported by the observation of the multiple peaks at the 2500$3000 \mathrm{~cm}^{-1}$ [22] which is not seen in our spectra. All of the above mentioned evidences show the formation of a chemical bound between VLD and CA. The IR spectra of TCNQ reported a $-\mathrm{C} \equiv \mathrm{N}$ stretch at $2223 \mathrm{~cm}^{-1}[22]$ and $\mathrm{C}=\mathrm{C}$ ctretching at $1619 \mathrm{~cm}^{-1}$. The chemical bound made between VLD and TCNQ is being exhibited on the IR spectra by the shifting of the nitrile group to 2253 $\mathrm{cm}^{-1}$ and disappearance of $-\mathrm{NH}$ peak at $3420 \mathrm{~cm}^{-1}$. The IR spectra of p-chloranil gives $\mathrm{C}=\mathrm{O}$ stretch at 1688 and $1677 \mathrm{~cm}^{-1}$ and $\mathrm{C}-\mathrm{O} 1315 \mathrm{~cm}^{-1}$. In the IR spectra of VLD- p-chloranil, again the $-\mathrm{NH}$ peak at $3420 \mathrm{~cm}^{-1}$ is being lost and a new $\mathrm{C}-\mathrm{N}$ stretch is being observed at $1103 \mathrm{~cm}^{-1}$ indicating the foration of a new C-N bound between VLD and p-chloranil molecules.

${ }^{1} \mathrm{H}$-NMR spectra of the CT Complexes

Our results obtained from the NMR study of VLD is in well agreement with the previously published data $[23,24]$. The most characteristic peaks of the NMR spectrum are the peaks at $4.70(0.8 \mathrm{H}, \mathrm{q})$ and $5.17(0.2 \mathrm{H}, \mathrm{d})$ $\mathrm{ppm}$ related to the isomers of the $\alpha$ proton of $\mathrm{C}-5$, a member of ring $\mathrm{A}$. The structure of VLD can be seen in Figure 2. The $\% 20$ occurrence of this proton in $\beta$ position causes the appearance of this proton in two different peaks in NMR spectrum. The second important point in the spectrum is the presence of all protons of the ring system $B$ in only two broadened singlet peaks at $1.40 \mathrm{ppm}$ for $8 \mathrm{H}$ (likely a singlet for $6 \mathrm{H}$ and a singlet for $2 \mathrm{H}$ under it, exposed around $1.39 \mathrm{ppm}$ ) and at $1.47 \mathrm{ppm}$ for $6 \mathrm{H}$. Although the first impression of the ring system $\mathrm{B}$ is 14 protons with different chemical environments, rotating the $3 \mathrm{D}$ structure of the structure around amine group shows the equal distances of all protons from the hydroxyl and amine groups at two sides of multi-cyclic system (Fig. 5) causing the occurrence of two broadened singlet peaks in the ${ }^{1} \mathrm{H}-\mathrm{NMR}$ spectrum. The $\mathrm{NH}-\mathrm{CH}_{2}$ protons are observed at $3.31 \mathrm{ppm}(2 \mathrm{H}, \mathrm{d})$, while the protons of etilene group neighbour to the nitrogen of pyrrolidine ring is observed at $\delta 3.41\left({ }^{1} \mathrm{H}, \mathrm{dd}\right)$ and $\delta 3.58\left({ }^{1} \mathrm{H}, \mathrm{m}\right)$. A broadened singlet at $\delta 4.39$ has been attributed to $\mathrm{NH}$ group.

Complexation of VLD with TCNQ, CA and p-chloranil caused the complete disappearance of the $\mathrm{NH}$ peak at $\delta 4.39$ which shows that all reagents make chemical bound with this group. Together with that, the above mentioned broadened singlet peak of eight protons at $\delta 1.40$ splits to two multiplet peaks at 1.42 and $1.54 \mathrm{ppm}$ corresponding to two and six protons respectively. Probably the attached reagent to the amine group causes a significant change in the chemical environment of the ring system B. Moreover the protons of $\mathrm{CH}_{2}-\mathrm{NH}$ show a shift to down field from $3.31 \mathrm{ppm}$ to $3.7 \mathrm{ppm}$ due to the connection of electrophilic groups to the neighboring $\mathrm{NH}$ group in the all cases. On the other hand, the presence of complexation agents prevents the formation of conformational isomers of the ring A which consequently decreases the ocurrence of the proton belong to $\mathrm{C}-5$ in $\beta$ position. This fact results in almost disappearance of the peak at $5.17 \mathrm{ppm}$. In case of complexation of VLD with TCNQ and p- chloranil, a new peak corresponding to one proton around 4 ppm demonstrates the reduction of the agent at the site of connection. Thus the suggested results of reaction between VLD and CA, p-chloranil and TCNQ is as shown in Figure 2. Since there is no significant diffrence between NMR spectra of VLD complexes, the spectrum of VLD-p-chloranil is given as example (Fig 5 and 6).

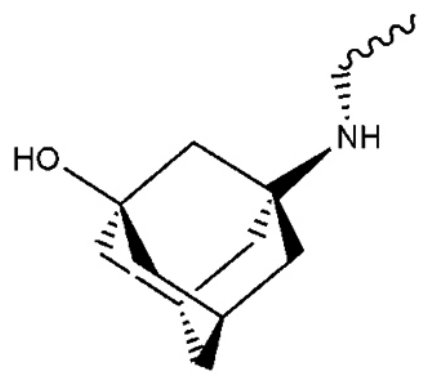

Fig.5 Chemical structure of ring system B

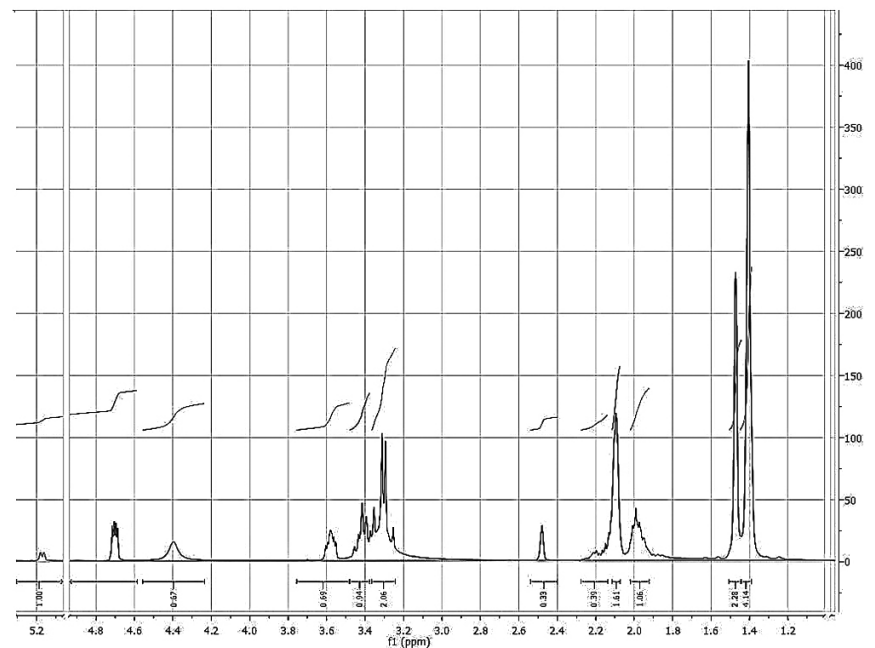

Fig.6 1H-NMR spectrum of VLD

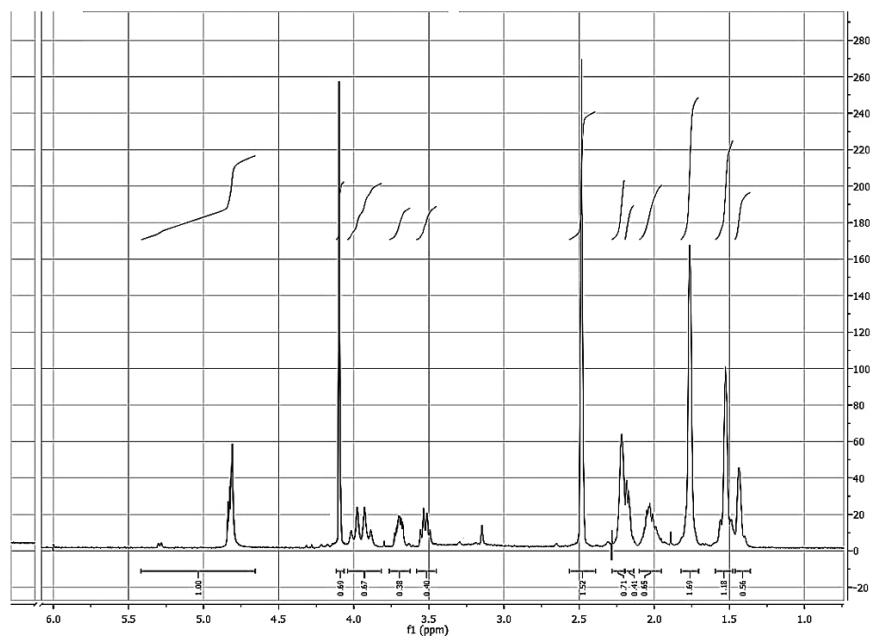

Fig.7 1H-NMR spectrum of VLD- p-chloranil complex

\section{CONCLUSION}

Three selective, simple and less time consuming spectrophotometric methods using for CA, p-chloranil and TCNQ reagents were described for determination of anticonvulsant drug substance VLD in this study. CA method was superior as compared with the other two methods according to higher molar 
absorptivity and lower detection limits. The described methods are suitable for the determination of VLD in pharmaceutical formulations without interference from excipients and can be easily applied to quality control laboratories for the routine analysis of VLD in raw materials and pharmaceutical formulations.

\section{REFERENCES}

1. W.K.H. Fakhoury, C. Lereun, D. Wright, Pharmacology 86, 44, (2010).

2. C.F, Deacon, Diabetes Obes. Metab. 13, 7, (2011).

3. M. Ligueros-Saylan, J.E. Foley, A. Schweizer, A. Couturier, W. Kothny, Diabetes Obes. Metab. 12, 495, (2010).

4. S. Halimi A. Schweizer B. Minic J. Foley S. Dejager, Vasc. Health Risk Manag. 4, 481, (2008).

5. B. Ahrén, A. Schweizer, S. Dejager, B.E. Dunning, P.M. Nilsson, M. Persson, J.E. Foley, Clin. Endocrinol Metab. 94, 1236, (2009).

6. V. Fonseca, A. Schweizer, D. Albrecht, M.A. Baron, I. Chang, S. Dejager, Diabetologia, 50, 1148, (2007).

7. V. Fonseca, M. Baron, Q. Shao, S. Dejager, Horm Metab Res. 40, 427, (2008).

8. J. Martin, W. Buchberger, J.L. Santos, E. Alonso, I. Aparicio, J. Chromatogr. B Analyt. Technol. Biomed Life Sci. 895, 94, (2012).

9. A.T. Barden, B. Salamon, E.E. Schapoval, M. Steppe, J Chromatogr. Sci. $50,5,(2012)$.

10. X. Wang, D. Zhang, W. Xu, H. Liu, W. Wang, Xenobiotica 40(10), 707,(2010).
11. R. Foster, Organic Charge-TransferComplexes, Academic Press, London, 1969.

12. L.R. Melby, in: S. Patai (Ed.), The Chemistry of the Cyano Group, Interscience, New York, 1970.

13. A. Oztunc, N. Dokumaci, E. Tahtasakal, Il Farmaco 54, 835, (1999).

14. M.S. Matos, M.H. Gehlen, Spectrochim. Acta A 60, 1421, (2004).

15. M. Hasani, M. Shamsipur, Spectrochim. Acta A 61, 815, (2005).

16. E.A. Taha, S.M. Soliman, H.E. Abdellatef, M.M. Ayad, Microchim. Acta, 140,175 ,

17. A.A. Gouda, Talanta 80(1) 151, (2009).

18. E. Khaled, Talanta 75(5), 1167, (2008).

19. A.A. Gouda, R. El-Sheikh, A.S. Amin, Chem. Pharm. Bull. 56(1), 34, (2008).

20. P. Job, Anal. Chem. 9, 113, (1928).

21. ICH, In: International Conference on Harmonization of Technical Requirements for Registration of Pharmaceuticals for Human Use, Validation of Analytical Procedures: Text and Methodology Q2 (R1), 2005.

22. A. Pawlukojć, G. Bator, L. Sobczyk, E. Grech, J. Nowicka-Scheibe, J. Phys. Org. Chem. 16 (10) 709, (2003).

23. F.A. Siddiqui, M.S. Arayne, N, Sultana, F. Qureshi, A.Z. Mirza, M.H. Zuberi, S.S. Bahadur, N.S. Afridi, H. Shamshad, N. Rehman, Eur. J. Med. Chem. 45 (7) 2761, (2010).

24. S. Winter, Process for Preparing Vildagliptin, U.S.P.A. Publication, Editor United States, 2008. 